\title{
Los territorios migratorios como espacios de articulación de migraciones nacionales e internacionales. Cuatro casos del contexto mexicano
}

\author{
Migrant territories as spaces of Articulation \\ of National And International Migration. \\ Four cases of mexican context
}

\author{
Sara María LARA Flores \\ Instituto de Investigaciones Sociales-UNAM \\ saralf@servidor.unam.mx
}

Recibido: 16.06.2011

Aprobado definitivamente: 13.12.2011

\section{RESUMEN}

La producción de flores, frutas y hortalizas en México conforman un sector sumamente dinámico en términos de rendimientos, valor de las exportaciones y empleos. Se trata de un sector que opera en forma depredadora, tanto de los recursos naturales en los espacios en los que tiene asiento, como de la fuerza de trabajo que utiliza, provocando a su alrededor una fuerte movilidad entre los trabajadores que intervienen en estos cultivos. Esta situación resulta paradójica, pues por un lado, muestra la existencia de una agricultura de vanguardia, altamente modernizada, comparable a la que existe en los países desarrollados y, por otro lado, esta agricultura se inserta en un contexto nacional de pobreza rural y deterioro generalizado de las condiciones de vida de los trabajadores.

Este artículo analiza cuatro casos dentro del contexto mexicano que dan cuenta del desarrollo de una agricultura sumamente moderna que está en manos de grandes empresas conectadas al capital global. Esta conexión de la agricultura local y el capital global está generando fuertes procesos de movilidad y circuitos de distinta naturaleza y con elevada densidad relacional en los cuales intervienen grupos diferentes (locales y migrantes, indígenas y mestizos, migrantes de retorno, circulares o población asentada). El objetivo de este artículo consiste en conocer la forma como, en torno a estas zonas de agricultura intensiva, se generan movilidades y se producen encadenamientos de migraciones nacionales e internacionales, el modo como se conectan con los mercados de trabajo a distinta escala, los mecanismos que favorecen la creación de pequeños núcleos de poblamiento que sirven de escalón para acceder a nuevos destinos y/o nuevos mercados, y la forma como cada grupo significa esos lugares de agricultura intensiva y hace de ellos una parte de su territorio de migración o de circulación.

Palabras clave: agricultura intensiva, jornaleros, trabajo agrícola, movilidades del trabajo, migraciones. 


\begin{abstract}
The production of flowers, fruits and vegetables in Mexico configure a highly dynamic sector in terms of performance, value of exports and jobs. This is a sector that operates in a predatory way, both of natural resources in areas where it is situated, and of the labor force used, resulting in around a high mobility among workers involved in these crops. This situation is paradoxical because, on the one hand, it shows the existence of an advanced agriculture, highly modernized, comparable to that available in developed countries and, on the other hand, this agriculture is inserted in a national context of rural poverty and of general degradation living conditions of workers.

This article examines four cases in the Mexican context that reflect the very development of modern agriculture is in the hands of large companies connected to global capital. This connection to local agriculture and the global capital is generating strong mobility processes and circuits of different types and spaces with a high relational density in which different groups involved (local and migrant, indigenous and mestizos, return migrants, circular or settled population). The aim of this paper is to see, at the level of these areas of intensive agriculture, how mobilities are generated and how chains of national and international migration are produced, the way they connect with the labor markets at several scales, the mechanisms favoring the creation of small clusters of settlements that serve as stepping stone to reach new destinations and/or new markets, and how each group give a meaning to those areas of intensive agriculture and make them a part of its territory migration or its movement.
\end{abstract}

KEYwORDs: intensive agriculture enclaves, day laborers, agricultural work, labor mobility, migration.

\title{
SUMARIO
}

1. Introducción. 2. Una producción que polariza. 3. El contexto local del nacimiento de regiones de agricultura intensiva. 4. Estrategias de crecimiento y de competitividad. 5. Deterioro de las condiciones de trabajo y "encadenamientos migratorios". 6. Conclusiones.

\section{SUMMARY}

1. Introduction. 2. A polarizing production. 3. The local context of the appearance of intensive agricultural regions. 4. Strategies for growth and competitiveness. 5. Worsening of working conditions and «migration chains». 6. Conclusions. 


\section{INTRODUCCIÓN}

La producción de flores, frutas y hortalizas en México conforman un sector sumamente dinámico en términos de rendimientos, valor de las exportaciones y empleos. El problema es que se trata de un sector que opera en forma depredadora, tanto de los recursos naturales en los espacios en los que tiene asiento, como de la fuerza de trabajo que utiliza, provocando a su alrededor una fuerte movilidad entre los trabajadores que intervienen en estos cultivos. Esta situación resulta paradójica, pues muestra la existencia de una agricultura de vanguardia, altamente modernizada, comparable a la que existe en los países desarrollados, inserta en un contexto nacional de pobreza rural y deterioro generalizado de las condiciones de vida de los trabajadores.

Andrés Pedreño ha señalado la exigencia de estas agriculturas para contar con una disponibilidad ilimitada de trabajo duro, proporcionado por un trabajador poco exigente, sometido a condiciones extremas y por lo regular en situación de vulnerabilidad, especialmente cuando se trata de migrantes. Y agrega: "a trabajos precarios trabajadores precarios" (Pedreño, 2009). Analiza cómo los que llegan a laborar en estas agriculturas intensivas vienen de mundos ya precarios. Son estos mundos precarios, de los que los trabajadores salen, los que construyen "la experiencia próxima", de una vida y unas condiciones de trabajo previas, con la cual los trabajadores comparan el presente o "las posibilidades de un futuro soñado" (Seefoo, 2005), y es lo que hace posible que las condiciones extremas de explotación que encuentran en las regiones de agricultura intensiva sean soportadas por los trabajadores.

Hoy en día, los cambios introducidos en las empresas para incrementar rendimientos, mejorar la calidad y hacer más eficiente el trabajo, se producen sobre una base de formas de empleo precario y condiciones laborales sumamente desfavorables. Quaranta nos dice que "no puede haber irreductibilidad de la precariedad sin poner en juego la acumulación del capital" (Quaranta, 2009). La respuesta por parte de los trabajadores es la movilidad.

Por un lado, vemos salir del sector agrícola a importantes contingentes de trabajadores agrícolas y campesinos para ir a laborar en servicios, construcción o pequeños comercios, lo que ha dado pie a hablar de "desagrarización", no por la desaparición de la actividad agropecuaria, como se argumenta a menudo, sino por el impresionante crecimiento de los ingresos no agrícolas en los hogares rurales. C. de Grammont señala al respecto, que este proceso da cuenta de la falta de centralidad de la actividad agropecuaria en los hogares rurales (2009).

Por otro lado, vemos incrementarse, día con día, la emigración de campesinos y trabajadores hacia los Estados Unidos, provocándose con ello un vacío de mano de obra en las zonas de agricultura intensiva $\mathrm{y}$, a veces, el despoblamiento total de ejidos y comunidades campesinas aledañas. Esta situación ha generado un encadenamiento de nuevos movimientos de población, ya que la salida de la población local que garantizaba la fuerza de trabajo necesaria a estas agriculturas es reemplazada por nuevos trabajadores en condiciones de mayor vulnerabilidad.

Se trata de un proceso que da cuenta de la existencia de las discontinuidades espaciales entre este tipo de zonas de agricultura intensiva, que conforman una especie de "nodos" del capital global, y las regiones de pequeña agricultura o de agricultura tradicional, las cuales se vuelven periféricas. La degradación de las condiciones de vida de la población de estas regiones periféricas, el desempleo provocado por la crisis de algunos productos agrícolas (caña de azúcar, café, tabaco, etc.) que antaño dinamizaban la economía de ciertos espacios rurales, el deterioro ecológico provocado por el modo de operar de la agricultura moderna, la falta de apoyos por parte del Estado para los pequeños productores, entre otras cosas, crea regiones con desarrollos desiguales. El problema es que estas desigualdades no permiten una complementariedad equilibrada, sino que producen espacios en competencia por los recursos naturales, los saberes de los productores y de los trabajadores, y por la fuerza de trabajo misma.

Los cuatro casos analizados en este artículo dan cuenta del desarrollo de una agricultura sumamente moderna, en manos de grandes empresas conectadas al capital global, en donde se generan fuertes procesos de movilidad a su alrededor; circuitos de distinta naturaleza en los cuales intervienen grupos diferentes (locales y migrantes, indígenas y mestizos, migrantes de retorno, circulares o población asentada), dando lugar a espacios de alta densidad relacional, como lo han señalado Hily y Ma Mung (2002). Es decir, son lugares de encuentros, de intercambios, de negociaciones; y, a la vez, espacios de 
cruce (carrefour), que movilizan solidaridades étnicas y recursos simbólicos, capacidades lingüísticas y creación de redes.

Puede decirse que alrededor de estos polos de desarrollo agrícola se produce un "cruce de escalas" que van de lo internacional a lo local, escalas no sólo geográficas sino de tiempos y de culturas que se ponen en contacto en estos lugares. ${ }^{1}$ Cada proceso de movilidad de los grupos que atraviesan o se instalan en estos espacios corresponde a itinerarios individuales y grupales particulares, a tiempos de vida diferentes, a la vez que la apropiación que se hace de los mismos responde a códigos culturales particulares. Es decir, se trata de una interconexión de los "territorios migratorios" (Tarrius, 2000) de grupos diferentes. ¿Cuál es el vínculo entre esos movimientos? y ¿cuál es la relación entre los distintos trabajadores que allí confluyen? Es decir, entre los que se van y los que llegan a reemplazarlos. Faret (2001) menciona que la movilidad puede ser vista como articulación de lógicas en las cuales el objetivo es el de sacar ventaja de las desigualdades espaciales. Es jugar sobre el espacio, en donde cada punto tiene atributos a partir de propiedades objetivas, así como de significaciones subjetivas. Estas preguntas guían el presente trabajo.

\section{UNA PRODUCCIÓN QUE POLARIZA}

La horticultura es un sector de la producción que en las dos últimas décadas ha crecido de manera exponencial no sólo en términos de superficie sino de rendimientos. En 1980, ocupaba apenas 1.8\% de la superficie cosechada a nivel nacional, lo que significó 303606 ha, para 2006 había aumentado el doble, llegando a 602498 ha, lo que representó $2.9 \%$ de la superficie nacional. En tanto que el valor de la producción pasó de $7.8 \%$ a $16.7 \%$ del valor de la producción nacional en esos mismos años. Por su parte, el valor de las exportaciones hortícolas ha crecido constantemente, pasando de representar $30.2 \%$ del total de las exportaciones agrícolas en 1982 a $48.8 \%$ en 1994 y a $49.0 \%$ en $2000 .^{2}$

En cuanto a la floricultura vemos que se expande notablemente en México desde 1980 a 2006, cuando pasa de 13450 ha a 25370 ha cultivadas. Pese a que el porcentaje de la superficie sembrada de flores es poco significativo en relación con el total de la superficie agrícola nacional $(0.1 \%$ en 2006$)$, el valor de estos productos resulta significativo en relación con la superficie que ocupan, sobre todo en los estados de México y Morelos. En 2006 el valor de la producción de flores ascendió a 4262566692 de pesos lo que representó $1.8 \%$ del valor de la producción agrícola nacional. ${ }^{3}$ No obstante, cabe mencionar que la floricultura logra la productividad más alta al interior del sector agrícola nacional, en comparación con otros productos, incluyendo las hortalizas. ${ }^{4}$

Ambos sectores productivos, hortalizas y flores, al igual que la fruticultura, presentan una alta rentabilidad gracias a la mundialización de la cadena agroalimentaria, así como al acceso preferencial que tienen en los mercados estadounidense y canadiense. No obstante, en la cadena agroagroalimentaria la hegemonía está dada por los distribuidores, especialmente por los grandes mayoristas. En México, dichos mayoristas se encuentran asentados en los mercados de abastos de las ciudades de México, Guadalajara y Monterrey, y tienen un papel importante en la distribución de la producción en el mercado nacional. Otra vía de distribución se da a través las cadenas de supermercados (Echánove, 1999). Por su parte, las exportaciones están en manos de brokers o compañías que comercializan la producción en los Estados Unidos y Canadá, o por las grandes empresas que manejan por sí mismas sus comercializadoras. Se trata de una "hiperconcentración" de la producción en torno a un número limitado de grandes empresas que, a la vez, controlan la producción de pequeños y medianos productores mediante formas de agricultura a contrato, o comprándoles su producción, ya que son estas grandes empresas las que cuentan con los empaques, sistemas de enfriamiento, de al-

\footnotetext{
${ }^{1}$ Agradezco a Laurent Faret esta idea desarrollada en el Seminario de Investigación sobre "Los territorios migratorios como espacios de articulación de las migraciones nacionales e internacionales”, CONACYT, Morelos, 24-25 de abril de 2008.

${ }^{2}$ Ver http://www.sagarpa.gob.mx:80//sistemas/siacon/siacon.html.

${ }^{3}$ Ibid.

${ }^{4}$ Ibid.
} 
macenaje, transportación, distribución y etiquetado de productos.

En Sinaloa, por ejemplo, en 1998 se registraron 590 empresas hortícolas que producen para la exportación. ${ }^{5}$ Son desde pequeñas empresas familiares hasta grandes empresas capitalistas que surten 102 empacadoras. Pero mientras siete empresas producen en superficies de entre 1,000 y 2,500 ha, 355 operan en superficies que van de dos a 20 ha. ${ }^{6}$ Estas empresas se localizan esencialmente en 4 municipios, 3 del centro (Culiacán, Navolato y Guasave) y uno en el norte (Ahome) del estado. De ellas, unas 300 exportan a Estados Unidos y las más grandes compran su producción a otros productores de diferente talla para exportarla bajo su propia marca (Lara y C. de Grammont, 2008).

Según el estudio de Mora y Maisterrena (2008), en 1999, 16 empresas dominaban la producción de hortalizas en el Valle de Arista, S.L.P. Hoy en día, quedan once empresas, dos de las cuales han incorporado sistemas muy modernos de producción bajo invernadero y exportan toda su producción. Al lado de éstas, subsiste, en los ejidos, un pequeño grupo de productores que venden para el mercado interno, a través de los comerciantes que dominan la Central de Abastos de Monterrey.

En cuanto a la floricultura, se calcula que en México existen alrededor de 10 mil floricultores de campo abierto. A principios de los noventa se identificaron entre cien y ciento cincuenta productores bajo cubierta que ocupan alrededor de 600 hectáreas de invernadero, la mayor parte de éstos ubicados en Villa Guerrero, Estado de México.? Durante 1995 había en el país 31 empresas exportadoras, la mayoría instaladas en el Estado de México, las que en su conjunto realizaron $80 \%$ del total exportado en ese año. Todas las empresas exportan a Estados Unidos, y sólo cinco a Japón, Canadá, Francia y Alemania. Como puede verse, la actividad florícola en el Estado de México es de gran importancia; actualmente representa $50.4 \%$ de la producción total nacional (Castro, 2008).

En el estado de Morelos, una sola empresa domina la producción de okra y, junto con tres grandes brokers, controlan la comercialización y exportación de este producto hacia los Estados Unidos. Empresa y brokers se apoyan en pequeños productores locales, que cultivan bajo la modalidad de "agricultura por contrato". De esta manera, dejan a los productores la parte de proceso de trabajo que más riesgos conlleva (Sánchez y Saldaña, 2008).

Es decir, se trata de sectores productivos sumamente dinámicos, pero, a la vez, fuertemente polarizados, de tal manera que no logran generar un desarrollo regional equilibrado ni permitir que los beneficios se extiendan, a largo plazo, a la población local ni a hacia los trabajadores migrantes que laboran en estos cultivos.

\section{EL CONTEXTO LOCAL DEL NACIMIENTO DE REGIONES DE AGRICULTURA INTENSIVA}

En Sinaloa, la producción de hortalizas inicia tempranamente a finales del siglo XIX ya con una orientación exportadora. El despunte de esta agricultura, sin duda estuvo asociado, primero con la apertura de canales de riego, y más tarde con la edificación de presas que da inicio en 1948. A partir de ese momento se crea toda una red de 11 presas que bañan los principales valles del estado. De esta manera, Sinaloa se convierte en el estado con mayor superficie irrigada del país (C. de Grammont, 1990).

Cabe mencionar la importancia que, desde sus inicios, ha tenido en el desarrollo de este sector la organización un sistema de producción con vistas a garantizar la calidad de una producción orientada netamente a la exportación, y, en este sentido, el papel que ha jugado la mano de obra femenina local en los empaques ("packings") de productos frescos para garantizar la calidad en la exportación. A la vez que, desde los años sesenta se hizo necesario el abastecimiento de mano de obra proveniente de otras regiones del país para laborar en las cosechas. No obstante, una constante en este sector ha sido la contratación de trabajadores en condiciones suma-

\footnotetext{
${ }^{5}$ A la fecha, los procesos de concentración han reducido el número a 322 empresas.

${ }^{6}$ Asociación de Agricultores del Río Culiacán, 1998; Directorio de Empacadoras de Sinaloa, 1999.

${ }^{7}$ Floricultura Intensiva, 1992.
} 
mente precarias que contrastan siempre con la modernidad de las grandes empresas que allí operan.

A partir de la década de los setenta puede hablarse de un "boom" de la horticultura sinaloense, que tuvo como detonante el bloqueo comercial a Cuba, por parte de los Estados Unidos, lo que canceló las importaciones provenientes de ese país y privilegió las importaciones mexicanas. Esta coyuntura sería crucial para el despunte de la producción de hortalizas en el estado de Sinaloa.

El desarrollo de grandes empresas agrícolas en la región de los valles, con superficies que van de mil a 2500 ha, contrasta con un entorno de agricultura tradicional y temporalera en la zona serrana de este estado. Es importante decir que las empresas hortícolas ubicadas en Sinaloa forman parte de una cadena agroalimentaria esencialmente de capital mexicano, pero para la distribución operan con base en asociaciones con capital norteamericano que domina la venta al menudeo o a través de los supermercados en el vecino país. Las empresas productoras-exportadoras de hortalizas frescas más grandes de Sinaloa tienen sus propias comercializadoras en diferentes puntos de los Estados Unidos, mientras las medianas venden a consignación a los brokers ubicados en los puntos fronterizos en Estados Unidos (principalmente Nogales) o venden su producción a las grandes empresas que cuentan con empaques y tienen los canales adecuados para cumplir las normas que requiere la exportación de productos frescos (Lara y C. de Grammont, 2008).

La acción de estas grandes empresas, desde hace ya más de cincuenta años, convirtieron a Sinaloa en un punto de atracción de trabajadores de la propia región y desde distintas partes del país. Es así que dio inicio la operación de contratistas o "enganchadores" en el abastecimiento de la mano de obra que requieren las empresas, haciendo coincidir la oferta y la demanda de trabajo. Sobre todo, porque la demanda más importante se concentra durante el invierno, en la temporada de cosecha, y la mano de obra local resulta insuficiente. Desde la década de los setenta dichos contratistas orientaron su mirada hacia las zonas indígenas de Oaxaca y Guerrero.
En los años ochenta, con el objetivo de producir para el mercado interno, las grandes empresas productoras de hortalizas de Sinaloa llevaron una parte de sus operaciones hacia el Valle de Arista en San Luis Potosí, ${ }^{8}$ para sembrar tomate y chile. De este modo, impusieron en esta región un modelo productivo basado en la abundancia de agua, como sucedía en Sinaloa, y transforman la ecología del valle al explotar intensivamente el agua subterránea mediante la construcción de pozos profundos. Esta zona, naturalmente desértica, se constituye, así, en una especie de oasis artificial basado en la sobreexplotación del agua subterránea. Junto con las condiciones climatológicas, el suelo -rico en potasio-, y la mano de obra disponible, permitieron el desarrollo agrícola y agroindustrial en esta región, pero provocaron un desastre ecológico (Mora y Maisterrena, 2008).

Con el riego, los agricultores comenzaron a necesitar gente para trabajar en los ranchos. No fue fácil, hacían visitas domiciliarias para invitar a la gente a trabajar con ellos. Dada la poca alternativa laboral, hombres y mujeres comenzaron a realizar este duro trabajo. Poblaciones que se dedicaban al tallado de lechuguilla, la caza en el desierto, la siembra de maíz de temporal, así como la cría de ganado menor, fueron abandonando estas actividades para trabajar como jornaleros en los ranchos agrícolas. Alquilarse como peones, aunque fuera de manera temporal, les proporcionaba un salario más seguro que el tallado de lechuguilla y las actividades tradicionales (Mora y Maisterrena, 2008).

La implantación del nuevo modelo agrícola revolucionó el trabajo en el valle, cambió las antiguas formas de trabajo de tipo familiar, por modernos sistemas de trabajo y sentó las bases para una división sexual y étnica de las tareas, a semejanza de lo que sería "el modelo sinaloense". La composición de la fuerza de trabajo se modificó, ya que la instalación de empaques demandó una importante cantidad de mano de obra, particularmente femenina. Como las tareas relativas a este proceso (selección y empaque), eran totalmente desconocidas por la población local, llegaron al valle de Arista mujeres especializadas en la selección y empaque de tomate, con el

\footnotetext{
${ }^{8}$ Este valle está ubicado en la parte centro del altiplano en San Luis Potosí, integrado por los municipios de Villa de Arista, Venado y Moctezuma, y la delegación de Bocas, municipio de San Luis Potosí. Tiene, una extensión territorial de 200000 hectáreas, de las cuales 15000 son de riego.
} 
fin de capacitar a la población local, sobre todo de mujeres viudas o separadas, ya que no era bien visto que las casadas o solteras trabajaran fuera de su casa. En el campo, en cambio, se emplearon mujeres y niños para las tareas de plantación y cosecha, población trabajadora compuesta por habitantes de las comunidades del valle y de migrantes indígenas originarios principalmente de los estados de Guerrero, Hidalgo y Oaxaca. La función de los enganchadores en esta tarea, también, se hizo necesaria.

En el caso de Morelos, Sánchez y Saldaña (2008) muestran la conformación de una zona de agricultura intensiva en un entorno eminentemente campesino que combina la agricultura comercial con el autoconsumo, y que en la actualidad se disputa los recursos (fuerza de trabajo, tierra y agua) con las empresas agroexportadoras y con otros sectores de la economía, principalmente con los grandes complejos inmobiliarios y de turismo.

Esta zona, cuna del movimiento zapatista durante la Revolución mexicana, que gozó del reparto ejidal, conformó un sector de pequeños productores, cuya actividad fue puntal para el abasto de materias para el desarrollo agroindustrial. Especialmente fue una zona cañera, por excelencia, productora de arroz y de otros granos, gracias a la abundancia de agua y sistemas de riego. La crisis de la industria azucarera implicó, a la postre, el cierre de ingenios y la clausura de una de las pocas fuentes de recursos para muchos productores, en varias regiones del país. En Morelos, los hogares rurales han desplegado diferentes estrategias de multiactividad que implican el empleo de uno o más miembros de la familia en labores agrícolas y no-agrícolas, entre otras en el sector de servicios, conduciéndolos, con frecuencia, a migrar.

En esta transformación del uso y manejo de sus recursos, los campesinos se han visto obligados a cultivar en asociación con empresarios externos en diferentes modalidades de agromaquila (Gómez y Caraveo, 1990), a rentar sus tierras o, en el caso extremo, a venderlas. Es así que llegan a este estado un grupo de empresarios texanos con el interés de producir angú, ${ }^{9}$ una hortaliza éxótica para México, que se consume en Estados Unidos. Entre las ventajas que encontraron es que mientras en ese país tenían que enfrentar las fuertes nevadas de invierno, en Morelos podían asegurar la producción en esta temporada. Es así, que llegaron varios intermediarios comerciales y empresarios a la región surponiente del estado de Morelos y al norte de Guerrero. ${ }^{10}$ Destaca la instalación de la empresa Río Grande, quien se instala primero en el estado de Guerrero, para después migrar a Morelos, en donde controla el mercado de este producto.

Al llegar a esta región, los brokers y empresas incorporan a pequeños productores, la mayoría de ellos ejidatarios que antiguamente producían caña de azúcar o arroz, junto con maíz y otros cultivos de autoconsumo, a la producción de una hortaliza que pocos conocen en el país y mucho menos la consumen, ya que va dirigida netamente a la exportación. Al mismo tiempo, crean todo un flujo de migración, proveniente de las regiones más deprimidas del estado de Guerrero, para participar en la cosecha de este producto (Sánchez y Saldaña, 2008).

Por su parte, la producción de flores en el Estado de México inicia en los primeros años de la década de los cincuenta, cuando un grupo de japoneses llega al municipio de Villa Guerrero con la finalidad de producir flores para su venta. Si bien en algunas comunidades de la región (como en Santa Ana Ixtlahuacingo, en el municipio de Tenancingo), la gente ya tenía cierta experiencia en el cultivo de flores, operaban como floricultores a pequeña escala. Este evento marcó al municipio en particular y a la región en general, porque años después se convirtió en el espacio más importante de producción de flor a nivel nacional (Castro, 2008).

A finales de los años cincuenta, poco a poco la producción de la flor fue desplazando al resto de las actividades económicas de la región. La llegada de los japoneses coincidió con una estrepitosa caída en las ventas del aguacate y el durazno, que se producían regionalmente, lo que orilló a los habitantes de Villa Guerrero a buscar otras alternativas laborales en la propia región. Ciertamente, desde principios de

\footnotetext{
${ }^{9}$ La okra o angú (Hibiscus esculentus o Abelmoschus esculentus), hortaliza de origen africano.

${ }^{10}$ La producción nacional de okra se destina casi exclusivamente al exterior, principalmente a Estados Unidos. En el año agrícola 2006 del total de la superficie cosechada, Tamaulipas aportó el 86\%, Morelos y Guerrero ocuparon en el segundo y tercer lugar, con el $8 \%$ y el $5 \%$ respectivamente. A pesar de esta modesta participación por parte del estado de Morelos, se debe señalar que el número de toneladas que se obtienen por hectárea en las tierras morelenses casi duplica los rendimientos de los otros estados.
} 
de esta década la producción de flor había alterado el mercado de trabajo local y las valoraciones que tenían los jornaleros en cuanto a los sistemas de trabajo; esto es, los japoneses pagaban más por la jornada de trabajo y contaban con una clara estructuración en los tiempos de trabajo y descanso, situaciones ambas que no estaban presentes en el cultivo del durazno, el aguacate y el pulque que se producían regionalmente. Con estas condiciones de trabajo más favorables se generó una importante oferta de mano de obra para la población local (Castro, 2008).

Castro (2008) menciona, que en un inicio, la floricultura fue una actividad muy marginal para los productores mexiquenses, pero, con el tiempo, éstos se interesaron en esta actividad, por lo que comenzaron la instalación de invernaderos propios. La competencia con estos nuevos productores, organizados en una asociación y apoyados por el Estado, llevó a los japoneses a retirarse de la región, no sin antes haber sentado las bases de una actividad de carácter intensivo.

En los últimos años de la década de los setenta, la región experimentó cambios muy significativos por el impacto de los invernaderos. De entrada, los invernaderos empezaron a absorber importantes cantidades de mano de obra gracias a que los salarios que pagaban por las jornadas de trabajo eran más altos que los acostumbrados en la región. También conformaron un mercado laboral muy robusto y transformaron los conocimientos en cuanto a la producción y comercialización de flores. De esta manera, al iniciarse lo proyectos empresariales, surgieron iniciativas que no sólo tomaron en cuenta de las potencialidades del clima para producir flor de alta calidad en la región, también tomaron en cuenta la experiencia previa que tenía la gente de la región en la producción de flor a cielo abierto.

Este cambio fue muy interesante porque, en un inicio, la mujer desplazó a los hombres en el trabajo de la flor. En gran medida, porque quienes tomaban las decisiones en las empresas consideraban que la delicadeza femenina era más apropiada para el manejo de las rosas. No obstante, en los hechos, es que la mujer ofrecía una mano de obra más barata y flexible, útil al despunte de esta actividad (Lara, 1998).

Como puede observarse, a través de estas experiencias locales, el desarrollo de una agricultura empresarial, en cada una de las regiones estudiadas, ha estado vinculado al desplazamiento de otros productos, a la incorporación de la población local en cali- dad de mano de obra asalariada y/o de productores "a contrato", como sucede en Morelos, así como a la explotación de tierra y agua, de manera intensiva. La instalación de empresas, brokers y otros agentes productivos, ligados a este tipo de producción, ha traído consigo nuevas modalidades de producir y de trabajar, y, si bien ha incorporado a las mujeres, lo ha hecho sobre la base de una segmentación sexual y étnica del trabajo, en la cual los indígenas migrantes realizan las tareas rudas y peor pagadas.

\section{ESTRATEGIAS DE CRECIMIENTO Y DE COMPETIVIDAD}

Una de las estrategias que han utilizado las empresas para lograr competitividad en los mercados ha sido la descentralización geográfica. En el caso de las hortalizas sinaloenses, algunas empresas productoras o comercializadoras deslocalizaron su producción, en la década de los ochenta, ubicándola en distintas regiones del país para aprovechar las diferencias climáticas. Así, mientras en Sinaloa y Sonora se cultivan hortalizas de invierno, en Baja California Norte y Sur el ciclo principal es en primavera-verano; en el noroeste se ubica el grueso de la producción orientada a la exportación, mientras en Jalisco, San Luis Potosí, Michoacán y Morelos se produce el grueso de la producción que va para el mercado interno. A la vez, algunas empresas funcionan desarrollado alianzas asociativas con unidades de producción a mediana escala, que operan en diferentes regiones del país, pequeños y medianos productores, una gran mayoría de ellos ejidatarios, que han ampliado también sus operaciones y diversificado sus productos.

Es así que llegan al Valle de Arista los productores sinaloenses, no sólo para aprovechar las ventajas climáticas del lugar y la abundancia de una mano de obra que se incorpora como asalariada, sino para situarse estratégicamente cerca de los mercados de abastos de las ciudades de Monterrey y Guadalajara, con fines de controlar el mercado nacional de hortalizas. Es, también, así, que llegan productores de hortalizas de Texas al estado de Morelos, después de haber pasado por Tamaulipas, con el fin de producir okra, en temporada de invierno.

Estas empresas, insertas en los mercados globales, han llevado a cabo importantes procesos de re- 
estructuración que abarcan distintos aspectos. Principalmente, han tenido que incorporar nuevos criterios de calidad y ampliar su oferta de productos, diversificando los cultivos. Las más grandes buscan tener una oferta todo el año, no sólo descentralizando su producción, sino des-estacionalizándola, gracias a la introducción de nuevas técnicas de producción en invernadero o bajo túneles de plástico. Para dar cuenta de ello, es importante mencionar que actualmente existen en el país 18127 invernaderos en 12540 ha, lo que nos da una superficie promedio de 0.7 ha. No obstante, existen diferencias importantes en la magnitud de los invernaderos por estado. Los más grandes, sin duda, se ubican en los estados de Sinaloa, Baja California, Sonora y San Luís Potosí. En cuanto al número de unidades, destaca el Estado de México en el cual se localizan 5034 unidades que abarcan 1868 ha, en el estado de Morelos existen 507 con 250 ha, en San Luís Potosí 233 en 313 ha y en Sinaloa 35 con 783 ha. (Censo Nacional Agropecuario de 2007).

La incorporación de tecnologías, las más modernas en el país, comparables con las que tienen en los países desarrollados, ha ido de la mano de nuevas formas de gestión del trabajo. No sólo vemos ponerse en marcha, desde los años sesenta y setenta, métodos de producción en cadena, sobre todo en el empaque y acondicionamiento de los productos para su venta, sino sistemas de organización que segmentan a la fuerza de trabajo por sexo y por etnia, con el fin de quebrantar cualquier posibilidad de unidad y movilización de los trabajadores. Cabe mencionar que la acción sindical es prácticamente inexistente en este tipo de agriculturas en México (Rau y Lara, 2008).

Las experiencias de estas regiones muestran lo que significó la imposición de estas nuevas formas de producir y de trabajar, no sólo diferentes de aquellas a las que estaba acostumbrada la población local, sino alienantes. El antiguo productor local abandona sus saberes complejos para convertirse en asalariado y ocuparse de un solo tipo de tareas en la cadena productiva: cortar flores, cosechar tomates, regar, fumigar o empacar. A la vez, la introducción de tecnologías modernas que buscan elevar rendimientos, incrementan la productividad de trabajador gracias a la eficiencia tecnológica, pero, sobre todo porque ésta se acompaña de sistemas de estímulos a la productividad, en el mejor de los casos, o de diferentes formas de coerción.
Los efectos que estas estrategias han tenido en el empleo y, por consecuencia, en la movilidad de los trabajadores han sido importantes. Por ejemplo, la deslocalización de las empresas sinaloenses en el Valle de Arista provocó el desplazamiento de los trabajadores locales, entre ellos el de las empacadoras de tomate, quienes, para ser fieles con la empresa y mantener su empleo, se vieron en la obligación de trasladarse a este valle. Dicho desplazamiento significaba irse por largos periodos a vivir en un lugar desconocido, sin familia y con pocos enseres personales. La diversificación de cultivos en Morelos, por parte de la empresa más importante en la producción de angú (Río Grande), llevó a modificar su esquema de contratación incorporando mujeres para ciertas labores en el cultivo de ejote, así como a migrantes de Guerrero, pero de otras regiones que no tenían experiencia migratoria.

En algunos casos, estas estrategias provocan la desaparición de ciertas tareas o de cierto tipo de trabajadores; en otros, conduce a la creación de nuevos puestos y al requerimiento de nuevas aptitudes o competencias. La introducción de invernaderos, o de producción bajo cubierta, en el caso de Sinaloa, por ejemplo, ha restringido o hecho desaparecer una serie de tareas de campo que realizaban los trabajadores procedentes de la zona serrana de ese estado. En tanto la des-estacionalización de la producción, por la introducción de invernaderos, ha disminuido la demanda de mano de obra migrante para la cosecha de hortalizas, la cual se concentraba básicamente en la temporada de invierno. Hoy en día, dicha demanda se ha extendido a lo largo de año, pero de manera escalonada y discontinua. Esto ha provocado fuertes cambios en los circuitos de migración.

Si bien no podemos hablar siempre de estrategias, es decir, de acciones concertadas para lograr determinados objetivos, uno de los fenómenos que se observa en la operación de estas empresas, es que cuando los recursos naturales (tierra y agua) han sido agotados, cuando los mercados dejan de ser atractivos para la obtención de ganancias o cuando la competencia en los mercados les resulta desfavorable, es común que dejen el lugar de asiento y se trasladen a otro, o simplemente se separen de la actividad. El daño que esto provoca remite inmediatamente a los trabajadores locales y altera los circuitos de los migrantes. 


\section{DETERIORO DE LAS CONDICIONES DE TRABAJO Y "ENCADENAMIENTOS MIGRATORIOS”,}

Los procesos de movilidad que se generan en las cuatro regiones que aquí estudiamos, muestran la complejidad de estrategias que ponen en marcha los trabajadores para hacer frente a la situación arriba mencionada.

Como lo hemos señalado, la producción de hortalizas y flores son altamente demandantes de mano de obra para realizar las labores culturales, pero especialmente al momento de la cosecha. Las tácticas de las empresas para contar con los trabajadores necesarios, en el momento adecuado, han sido múltiples y dependen, en gran parte, de situaciones locales y coyunturales. No obstante, movilizan, en primer lugar, a la población local o de regiones aledañas, pero para la cosecha vemos que se recurre regularmente a la contratación y enganche de trabajadores migrantes de regiones más desfavorecidas. Así, ha prevalecido la contratación de población indígena, originaria de regiones con altos grados de marginación, que llegan a las zonas de agricultura intensiva a realizar las labores más pesadas.

En Sinaloa y en el Valle de Arista en San Luis Potosí, el modelo ha sido la contratación de familias indígenas de los estados de Guerrero y Oaxaca, principalmente de municipios de alta marginalidad, mientras la población local realiza las tareas de empaque, supervisión, y asegura las labores de riego y fumigación. Son también choferes, tractoristas, encargados de almacenamiento, transporte y gestión administrativa, aunque, como hemos visto, las mujeres siempre se han hecho cargo del empaque y acondicionamiento de hortalizas y flores. En Valle de Arista estas mujeres fueron migrantes "calificadas" que llegaban con el personal de confianza de las empresas sinaloenses. En Morelos, ha sido tradición la participación de jornaleros indígenas del estado de Guerrero para el corte de caña, y, ahora, para la cosecha de distintas hortalizas, entre ellas el angú. Mientras en el Estado de México se ha echado mano de la población local, principalmente de mano de obra femenina.
Los procesos de reestructuración han llevado a intensificar el trabajo y a incrementar la productividad del conjunto de los trabajadores: locales y migrantes, contratados con salarios bajos y cero prestaciones sociales, ${ }^{11}$ en la mayoría de los casos. Con la crisis, los asalariados han perdido capacidad de compra, ya que los salarios se vuelven, día con día, insuficientes, por lo cual una de las tendencias más importantes ha sido el abandono del trabajo en el sector agrícola y/o la migración hacia Estados Unidos.

La migración de la población local o su salida del sector agrícola se ha convertido en una tendencia en los cuatro casos estudiados. Esto provoca un desajuste en la oferta de mano de obra y crea un vacío que lleva a las empresas a poner en marcha distintas estrategias de aprovisionamiento de mano de obra, y genera un proceso que pudiera ilustrarse como un movimiento en forma de cascada, en donde la migración internacional de la población local desencadena otros movimientos a distintos niveles.

Este fenómeno es especialmente claro en el caso del Estado de México, cuya región florícola constituye, hoy en día, una de las regiones de mayor densidad migratoria de ese estado, por la cantidad de individuos que han emigrado a los Estados Unidos. La carencia de esta mano de obra local, mujeres y hombres, ha sido resuelta por los empresarios locales a través del remplazo por migrantes originarios de los estados de Chiapas, Tabasco y Veracruz. Se trata de una población, que sufre la crisis por la que atraviesan los productos tradicionales, que constituyeron la materia prima de la industria alimentaria durante décadas: caña de azúcar, café, tabaco, ${ }^{12}$ entre otros, y los ha convertido en migrantes (Castro, 2008).

Por su lado, los jornaleros que tradicionalmente han llegado a las zonas hortícolas, en una suerte de movimiento pendular de sus pueblos de origen a los lugares donde se concentra la demanda, han debido complejizar sus circuitos de migración. A medida que la crisis de la agricultura avanza, afectando las zonas de agricultura tradicional, y que el Estado se ha retirado de su función como regulador de la actividad agropecuaria, el número de trabajadores agrícolas crece, en tanto que han salido del sector

\footnotetext{
${ }^{11}$ La mayor parte del los trabajadores agrícolas en México no cuentan con pago de séptimo día, ni de vacaciones o reparto de utilidades. Si bien existe una Ley que les otorga cobertura médica, ésta no se aplica o se hace en forma deficiente.

12 También conocida como quingombó.
} 
agrícola alrededor de tres millones de personas. ${ }^{13} \mathrm{La}$ falta de opciones de empleo en sus propias comunidades de origen, así como de apoyo para cultivar sus tierras, ha convertido a los campesinos pobres en jornaleros itinerantes, casi nómadas, que conectan distintos lugares siguiendo las cosechas de determinados productos, en un movimiento de carácter circular. Van de un lugar a otro, ya que las empresas que los contratan han impuesto una flexibilidad extrema en las formas de trabajo, contratándolos y despidiéndolos de acuerdo a sus conveniencias.

El retiro de las empresas sinaloenses en el Valle de Arista, después de haber agotado los mantos acuíferos y salinizado los suelos, ha tenido un fuerte impacto en la población local y ha transformado los circuitos de migración de los trabajadores originarios de Oaxaca y Guerrero, quienes ahora, ante la baja demanda que existe en esta región, han buscado nuevos destinos, siguiendo un circuito que va detrás de las cosechas de tomate en Yirécuaro, Michoacán y en los valles de Sinaloa. Por su parte, la población local, de origen campesino, que se incorporaron al "modelo sinaloense", trabajando en distintas tareas cuando dicho modelo estaba en auge, hoy en día han abandonado sus tierras y sus comunidades para irse a las ciudades de Monterrey o Tamaulipas a trabajar como albañiles o en el sector servicios, mientras las mujeres se insertan como empleadas domésticas. Sin embargo, un grupo, cada día más grande, ha cruzado la frontera en forma ilegal para irse a laborar, en estos mismos sectores, pero del lado americano. Ejidos y comunidades han quedado abandonadas y, con ellas, los más viejos, los abuelos. Los jóvenes, en cambio, han perdido todo contacto con sus lugares de origen. En remplazo, las empresas han ido a buscar trabajadores provenientes de los estados de Hidalgo y Veracruz, al igual que sucede en el Estado de México, pues se trata de una población indígena carente de experiencia migratoria, cuyas regiones de origen se encuentran afectadas por la crisis de los productos tradicionales.

Por su lado, en Sinaloa el proceso ha sido más complejo, pues la población serrana, que en su mo- mento garantizó las labores cotidianas del cultivo de hortalizas, hoy migra regularmente a otro estado del país ${ }^{14}$ o a los Estados Unidos. No solo porque los salarios que hoy encuentran en los valles se han estacando, mientras el costo de la vida se ha incrementado, sino porque especialmente Sinaloa es un estado fuertemente afectado por la violencia del narcotráfico. ${ }^{15}$ Sin embargo, los migrantes indígenas, originarios de Guerreo y Oaxaca, que habitualmente llegaban por largas temporadas a trabajar en las cosechas, para después regresar a sus lugares de origen, dieron paso a una migración de tipo circular que abarcaba los estados de Baja California y Baja California Sur, así como Sonora, siguiendo las cosechas de hortalizas y uva (C. de Grammont y Lara, 2004). Pero, poco poco, a lo largo de los últimos diez años, se fueron quedando en alguno de estos lugares de tránsito. El caso analizado por Lara y C. de Grammont (2008) da cuenta del fenómeno de creación de nuevos asentamientos de población indígena migrante que se ha ido quedando a vivir en torno a las zonas de agricultura intensiva de los valles de Culiacán, en Sinaloa, y desde allí construyen sus redes para atravesar la frontera.

Sucede algo similar en el caso de Morelos con una parte de los jornaleros indígenas migrantes. Los reajustes que han tenido lugar en la empresa más importante productora de angú, han llevado a los jornaleros, originarios del estado de Guerrero, a extender sus circuitos de migración y diversificar los cultivos en los que participan. Llegan a las cosechas de angú, ejote y otras hortalizas en Morelos, pero después se siguen al noroeste del país a trabajar en la cosecha de hortalizas en Sinaloa y de manzanas en Chihuahua, para después regresar a su lugar de origen; algunos, incluso, en este itinerario cruzan la frontera con los Estados Unidos. No obstante, una parte de ellos se han ido quedando en zonas periféricas a las de cultivo, aprovechando que la diversificación de cultivos que ha puesto en marcha la empresa Río Grande y otros pequeños productores, les abre nuevas fuentes de empleo.

En otro texto ya he analizado cómo, no obstante que la instalación de estas familias jornaleras en

\footnotetext{
${ }^{13}$ De acuerdo con datos de la Encuesta Nacional de Empleo (INEGI), los trabajadores habían pasado de representar el 54\% del total de los sujetos agropecuarios en 1993 a $57.3 \%$ en 2003.

${ }^{14}$ Baja California, Baja California Sur, Sonora o Jalisco.

${ }^{15}$ Es el caso de los municipios de Sinaloa de Leyva, Choix, Mocorito y Badiguarato, en ese estado de la República Mexicana.
} 
las regiones de agricultura moderna crea malestar a los lugareños, en gran parte porque son pobres y por su origen étnico, resulta perfectamente funcional a las empresas agrícolas el asentamiento de estos jornaleros. Son mano de obra disponible en todo momento sin que las empresas tengan que asumir los gastos de reproducción social (alojamiento, educación, salud, etc.) de los trabajadores migrantes que contratan; son los que se encargan de enganchar, alojar, transportar y aprovisionar de bienes a otros trabajadores migrantes que llegan "por su cuenta". ${ }^{16}$ Algunos de los ya instalados logran construir en sus predios "cuarterías" ${ }_{17}$ que alquilan a los jornaleros que llegan a trabajar temporalmente en las cosechas; los que pueden compran camiones que sirven para el traslado de los jornaleros desde las cuarterías a los campos de trabajo ("camioneteros"); los más abren un pequeño comercio en donde venden, a crédito ("fiado"), alimentos e insumos necesarios para los trabajadores. Así, los asentados encuentran un negocio en el circular de familiares, paisanos, o aun de descocidos, lo que a la vez los mantiene informados sobre los distintos lugares por donde éstos transitan, ampliando sus redes de relaciones (Lara, 2008).

Este circular de población local y de migrantes, encadena movimientos de carácter nacional e internacional cuyo punto de cruce son estas regiones de agricultura intensiva. Es decir, mientras unos salen de allí, por no encontrar las condiciones favorables de empleo ni de vida, otros llegan allí porque en su condición de indígenas, expulsados por la pobreza y la crisis de los productos en sus lugares de origen, hallan que las condiciones de trabajo que se les ofrecen, si bien precarias, son mejores que las que han dejado atrás.

Es así que estas regiones de agricultura intensiva se vuelven puntos de cruce de distintos grupos sociales: los que llegan, los que se van, los que transitan. Sin embargo, para cada uno de ellos, este lugar junto con todos aquellos por los que han pasado, o incluso aquellos que aun están en el imaginario como posibilidad futura, forman parte de su itinerario y de su territorio migratorio (Tarrius, 2000).
Son lugares en los que coinciden: población local y migrantes; indígenas y no indígenas; jornaleros sin tierra y pequeños productores. Todos vinculados, de una o de otra manera a la lógica y la dinámica de la operación de grandes empresas en torno a una agricultura intensiva de carácter global, pero poniendo en marcha sus propias estrategias.

En el Estado de México, la mano de obra femenina local encargada del corte y manejo de flores en los invernaderos, así como de su empaque, por una supuesta habilidad y delicadeza innatas, ha sido sustituida por hombres indígenas y mestizos migrantes, que antes de llegar a laborar en las flores cortaban caña con machetes y la cargaban en sus espaldas para subirla los camiones a donde se les transporta, en jornadas de más de 12 horas diarias. Para ellos el trabajo en la floricultura "es como un juego" frente al trabajo que antes realizaban, mejor pagado en comparación con lo que recibían por el corte de caña y en condiciones laborales menos penosas. Comparando pasado y presente, la zona florícola resulta un lugar de bienaventuranza.

Quienes han dejado el Valle de Arista, pocas veces vuelven la cara hacia él. Es un lugar de vaciamiento, donde sólo han quedado los viejos y los sin futuro. Es la imagen del desastre, frente a un porvenir que se imagina del otro lado de la frontera, a pesar de que se llega de manera ilegal y se trabaja en los peores oficios.

Estas imágenes dan cuenta de que los encadenamientos no sólo vinculan lugares, sino imaginarios que se construyen en torno espacios, que por ser apropiados real o simbólicamente se convierten en territorios. Territorios en los cuales entran en contacto culturas diferentes y se confrontan estrategias: las de los empresarios y las de los trabajadores, pero, también, las de los distintos tipos de trabajadores. Es por ello que retomamos la idea de Hily y Ma Mung (2002) de que se trata de espacios de alta densidad relacional. A la vez que son lugares en donde se entrecruzan los itinerarios de estos diversos grupos que allí coinciden, en torno a una zona de agricultura intensiva.

\footnotetext{
${ }^{16}$ La mayor parte de los jornaleros migrantes que llegan a estas regiones lo hacen mediante "enganchadores" o contratistas, Ver C. de Grammont y Lara, 2004 y Sánchez, 2006.

${ }^{17}$ Las "cuarterías" son habitaciones construidas por contratistas, transportistas o mayordomos, en sus propias casas o en algún terreno, en donde dan alojamiento a los migrantes que llegan a trabajar. Les cobran por semana y muy seguido ofrecen también el servicio de alimentación. Algunos de estos agentes son antiguos jornaleros migrantes ya establecidos.
} 


\section{CONCLUSIONES}

Los cuatro estudios de caso que analizamos en este artículo dan cuenta de los procesos de formación de polos de desarrollo agrícola, la forma particular como se consolidan, entran en crisis, se reestructuran y vuelven a reconfigurarse. No obstante, el interés está puesto en la manera como estos procesos crean mercados laborales y "se construyen vulnerabilidades" adaptadas a los contextos locales, creando una fuerza de trabajo "desechable" (Pedreño, 2009), que se ve obligada a migrar, encadenando movimientos en distintas direcciones.

La implantación de grandes empresas dedicadas a la agricultura intensiva y sus estrategias de reestructuración provocaron cambios importantes en las regiones en las cuales se asientan. En primer lugar, vemos que se desplazan productos y actividades tradicionales, para imponer nos sólo nuevos productos sino nuevas formas de trabajar y de producir, despojando a los habitantes locales de los saberes que antes les permitían explotar su medio ambiente. En segundo lugar, observamos el carácter itinerante que pueden tener dichas empresas al instalarse en una región, la cual, eventualmente, pueden abandonar cuando ya no conviene a sus intereses o cuando han provocado un fuerte deterioro ecológico. En tercer lugar, notamos que al momento en que dichas empresas realizan reestructuraciones que reducen el empleo o que imponen condiciones laborales de mayor exigencia de sobreexplotación, o cuando los capitales deciden retirase de una región, la población no retorna a sus antiguas actividades y es común que abandone la agricultura y/o salga de la región. El nivel de despojo ha sido tal que esta población, de origen rural y campesino, cambia de actividad productiva o migra hacia otras regiones del país o hacia los Estados Unidos. La respuesta de los trabajadores: locales o migrantes es la movilidad.

Así, nos ha interesado conocer la forma como, en torno a estas zonas de agricultura intensiva, se generan movilidades y se producen encadenamientos de migraciones nacionales e internacionales, el modo como se conectan con los mercados de trabajo a distinta escala, los mecanismos que favorecen la creación de pequeños núcleos de poblamiento que sirven de escalón para acceder a nuevos destinos y/o nuevos mercados, y la forma como cada grupo significa esos lugares de agricultura intensiva y hace de ellos una parte de su territorio de migración o de circulación.

Tarrius (2000:56) señala que esas poblaciones móviles "enganchan todos los lugares recorridos por ellas mismas, y otros reconocidos como cercanos, a una memoria de naturaleza colectiva". Todo territorio resulta, así, de un proceso de apropiación de un espacio, por un grupo social, con el objetivo de asegurar su reproducción (Le Berre, 1992: 623). En este caso, se trata de un proceso mediante el cual los trabajadores no sólo transitan por los lugares en donde trabajan sino hacen de ellos parte de sus espacios de reproducción y los construyen como territorios de migración. 


\section{BIBLIOGRAFÍA}

Carton De Grammont, H. (2009). "La desagrarización del campo mexicano", en Convergencia Revista de Ciencias Sociales, UAEM, México.

Carton De Grammont, H. y Lara, S. M. (2004). Encuesta a hogares de jornaleros agrícolas migrantes en regiones horticolas del noroeste del pais, Instituto de Investigaciones Sociales-UNAM, México.

C. De Grammont, H., Lara, S.M. y Sanchez, M.J. (2004). "Migraciones rurales y nuevas configuraciones familiares: Los casos de Sinaloa, México; Napa y Sonoma, U.S.A." en Marina Ariza y Orlandina de Oliveira, Imágenes de la familia en el cambio de siglo, Universo familiar y procesos demográficos contemporáneos, IIS-UNAM, México, pp. 357-368.

CASTRO, P. (2008). "Floricultura, redes migratorias y mercados de trabajo", Informe Final, Proyecto CONACYT (44249), México.

ECHÁNOve, F. (1999). "Los empresarios hortícolas y sus procesos de integración y diversificación”, en H. C. De Grammont (coord.) Empresas, reestructuración productiva y empleo en la agricultura mexicana, IIS-UNAM/Plaza y Valdés Editores.

Gómez Cruz, M. A. y Caraveo, F. (1990). "La agromaquila agrícola: una nueva forma de penetración de las trasnacionales", en Comercio Exterior, vol. 40, num.12, diciembre, pp. 1193-1199.

Hily, M.A. y Ma Mung, E. (2002). «Categories et lieux de circulations migratoires», Rapport de Recherche, INRE, $235 \mathrm{p}$.

INEGI (2007). Censo Nacional Agropecuario de 2007, México.

LARA, S. M. (1998). Nuevas experiencias productivas y nuevas formas de organización flexible del trabajo en la agricultura mexicana, Procuraduría Agraria y Juan Pablos Editor, México.

Lara, S.M. y C. De Grammont, H. (2008) "Reestructuraciones productivas y encadenamientos migratorios en las hortalizas sinaloenses", Informe Final, Proyecto CONACYT (44249), México.

Le Berre, M. (1992). “Territoires”, en Bailly, F. et al, (dir.) Encyclopedie de geograpie, Economica, Paris, pp. 617-637.

Ma Mung, E. (1999). “La dispersión comme resource”, en Cultures \& Conflits, núm. 33-34, pp. 89-103.

Mora I. y Maisterrena, J. (2008). "Movilidad laboral y encadenamientos migratorios en torno a un sistema de agricultura intensiva en el Valle de Arista, S.L.P.”, Informe Final, Proyecto CONACYT (44249), México.

Pedreño, A. (2009). "La Construcción Social de la Disponibilidad y Vulnerabilidad de los Trabajadores Inmigrantes Extracomunitarios en las Agriculturas Intensivas Mediterráneas", en Seminario Trabajo, Migración, Sindicatos y Actividades Laborales no Clásicas, Casa de la Primera Imprenta, UAM, 13 de febrero de 2009.

Quaranta, G. (2007). Comentarios a la sesión "Perspectivas teóricas y metodológicas para la investigación sobre migraciones y cadenas globales agrícolas en Latinoamérica", en Seminario Migraciones, Trabajo y Cadenas Globales, Murcia, 27-30 de enero de 2007.

RAU, V. H. y LARA S. M. (2007). "Bases territoriales para la organización de los asalariados agrícolas", $5^{\circ}$ Congreso Europeo CEISAL de Latinoamericanistas, Bruselas, 11-14 de abril.

SÁnchez, K. (2006). Los capitanes de Tenextepango. Un estudio sobre intermediación cultural, Miguel Ángel PorrúaUAEM, México.

SÁnchez, K. y Saldaña, A. (2008). "Nuevos espacios de articulación migratoria: el caso de la okra en Morelos" Informe Final, Proyecto CONACYT (44249), México.

SeEfoo, J. L. (2005). La calidad es nuestra, la intoxicación ... ide usted!, El Colegio de Michoacán, Zamora, Mich.

TARRIUS, A. (2000). "Leer, escribir, interpretar. Las circulaciones migratorias: Conveniencia de la noción de "territorio circulatorio'. Los nuevos hábitos de la identidad.” Relaciones num. 83, vol. XXI, pp. 39-66. 